\title{
Visualizations Supporting Knowledge-Based Decision Making in Cultural Heritage Management
}

\author{
Meliha HANDZIC \\ International Burch University, Francuske Revolucije bb, 71210, Ilidza, Bosnia and Herzegovina; (D) \\ meliha.handzic@ibu.edu.ba
}

\begin{abstract}
This paper explores the role of knowledge visualization in facilitating decision-making in cultural heritage management. The paper addresses the issue in the specific context of stećci - the tombstones from medieval Bosnia inscribed on the UNESCO world heritage list. Grounded in the distant reading paradigm, the paper introduces a series of visualizations of spatial, temporal, architectural, iconographical, epigraphical, and impact analyses of stećci data. Together, these visualizations should enable decision-makers to gain an enhanced understanding and knowledge of this important cultural heritage. In turn, this should help them make better decisions regarding their protection and promotion.
\end{abstract}

\section{Keywords}

knowledge management; visualization; decision-making support; cultural heritage management.

\section{Introduction}

In the last twenty years, cultural heritage management has become one of the key policies of the European Community (CE, 2005). Heritage is seen as cultural capital and a driver for tourism. The challenge for cultural heritage management is to strike the balance between generating revenue through tourism and preserving and promoting educational, historical, and cultural values of heritage assets.

Decisions regarding cultural heritage management depend highly on the collection and utilization of a wide variety of data related to these assets. In the past, these decisions were mainly made based on limited and non-systematic documentation and technology (Kioussi et al., 2013). Such an approach was not effective, as decisions were adversely affected by taking into account varying parameters and weights. This often threatened the implementation of inappropriate interventions.

It is argued here that proper data collection and presentation should enable enhanced understanding and knowledge of the heritage assets and thus support the decisionmaking process aimed at the protection and promotion of cultural heritage. In the knowledge management literature, visual presentations in the form of knowledge diagrams and maps are considered as important means for bridging understanding and communication (Gavrilova, Kudryavtsev, \& Grinberg, 2018). However, many challenges emerge from the wide variety of heterogeneous cultural heritage metadata, a wide spectrum of innovative visualization types, and diverse users with different abilities and aspirations (Windhager et al., 2019).

The purpose of this paper is to address this challenge in the context of stećci - the monumental tombstones from medieval Bosnia inscribed on the UNESCO world heritage list (World Heritage Convention, n.d.). In particular, grounded in the distant reading paradigm (Morretti, 2013), the current paper introduces a series of visualizations of spatial, temporal, architectural, iconographical, epigraphical, and impact analyses of

\section{How to cite}

Handzic, M. (2021). Visualizations Supporting Knowledge-Based Decision-Making in Cultural Heritage. Culture. Society. Economy. Politics, 1(2), 32-40. https://doi.org/10.2478/csep-2021-0009 ISSN (online) 2810-2010 
stećci data. It is expected that they would jointly represent a sound basis for knowledgebased decision-making that would establish priorities for protection and promotion.

The article is divided into five main sections: the first section introduces the main purpose of the article; the second section reviews relevant literature; the third section describes the application of visualization in support of decision making to the specific heritage case (i.e. stećci). The fourth section discusses the main findings, their implications and limitations, and proposes future research directions; the final fifth section concludes the article by stating its key contributions.

\section{Literature review}

\section{Decision-making in cultural heritage management}

Since the 1990s the European Union has developed several policies that focus on the valorization of heritage and its relations with communities and society. The Council of Europe convention from 2005 places cultural heritage at the center of its new vision for sustainable development (CE, 2005). The text deals with heritage as an object of individual rights, addresses the right to cultural heritage, the right to participate in culture, develops the idea of common heritage, defines heritage as a primary resource for sustainable development, provides the basis for the cultural environment, promotes the idea of heritage communities, and requires international and transnational cooperation.

While this framework convention was necessary to ensure that cultural heritage and culture, in general, get their rightful place, it does not create obligations to specific actions. It is left open to responsible parties to make decisions most suited to their traditions, law, policy, and practice. Choosing among different alternatives for valorization and promotion of cultural heritage is generally a complex decision-making process, given the multi-dimensional nature of the decisions and the wide set of values they represent (Della Spina, 2019).

According to Della Spina (2016), all decisions concerning the development, transformation, upgrading, and enhancement of historical heritage are characterized by a multi-dimensional profile of the objectives, often conflicting and influenced by each other. These are, by their very nature, complex decision problems. As such, they increasingly require the use of adequate methods and tools to support the decisionmaking process. In this way, the heritage evaluation process can be made more transparent and efficient.

Findings from a summary of various application examples indicate that different decision methods were used to facilitate people's decision-making processes. Popular multi-criteria methods (MCDM) that were illustrated include the application of the classical Analytic Hierarchy Process (AHP) and Delphi Methods (Della Spina 2016). More recent Social Multicriteria Evaluation (SMCE) and New Approach to Imprecise Assessment and Decision Environments (NAIADE) were found particularly useful in heritage evaluation, as they allowed structuring of a multi-criteria and multi-group model in this fuzzy field to reduce conflict and reach a degree of consensus (Della Spina, 2019; Munda, 2004).

While the above findings point to certain methodological improvements to classical techniques, it is argued here that they must be matched by efforts to improve data/information presentation to facilitate interpretation and thus lead to improved judgment and/or choice. In this respect, visualization emerged as an area of research and practice that may play an important role in supporting efficient and effective 
decision-making in cultural heritage management. The next section provides an overview of the current trends and achievements.

\section{Visualization in knowledge management}

The theme of visualization is a long-standing research interest in knowledge management. While the number of works devoted to the theme of visualization continues to grow, a recent literature review by Gavrilova, Alsufyex, and Grinberg (2107) identified the fragmented nature of visualization research, divided between several theoretical models and empirical consulting projects. The review also revealed the lack of work providing an understanding of how to apply visualization techniques by business managers. Yet, the visual representation of knowledge has been pointed out as a key dimension of modern knowledge management to support managerial judgment and decision making. Essentially, visualization represents a way to enhance decision performance by transforming raw data and information into forms that enable knowledge extraction.

The existing visualization formats are highly varied and numerous. Stabellini, Remondino and Tamborrini(2017) presented a collection of ninety-six types of visualization graphics based on different functional and structural taxonomies. Common formats range from structured text and tables, through heuristic sketches, conceptual diagrams, visual metaphors, knowledge maps, to interactive visualizations and animations. In addition, numerous digital tools have been developed applying different graphic means and advanced digital technologies. A list of some of the most popular general-purpose, as well as some special-purpose visualization tools is maintained online by Liu (2016).

According to Bai, White, and Sundaram (2012), visual representations can be applied to the following three contexts: the problem context concerned with the situations to be supported; the knowledge worker context related to any aspect that can affect the adoption of visualization by different stakeholders; and the purpose context containing information about what a knowledge worker is trying to achieve through visualization. Building on the above idea, Eppler and Burkhard (2007) suggest that effective knowledge creation and transfer through visualization requires the consideration of at least five questions about knowledge visualization: what (content), why (purpose), who (target group), where (context) and how (format).

Findings from a summary of various application examples indicate that different visualization formats facilitated different knowledge management tasks. For example, structured text/tables and conceptual diagrams were best suited for codification; mental images/stories and metaphors for transfer and application; knowledge maps for identification; and heuristic sketches and interactive visualizations for creation of knowledge (Handzic \& Dizdar, 2016). Furthermore, preliminary findings reveal that visual approaches have the potential to improve decision-making during operations in established firms (Aas \& Alaassar, 2018). As a result, visualization is emerging as an important area of research that explores its role in knowledge management, particularly for managerial decision-making.

So far, the issue of visualization has not been adequately addressed in the context of cultural heritage management. One notable exception is a recent review of visualization approaches for cultural heritage collections by Windhager et al. (2019). It reflects on the current state of the art and points out opportunities for future research in both design evaluation and the process of interpretation. Responding to the call for more research, of special interest to this article, is to explore the role of visualization as a knowledge management tool for supporting the decision-making process in a specific case of cultural heritage management described in the following section. Such a tool is considered extremely strategic, especially if adopted during the planning stage (Della Spina, 2016). It is expected to play a role in supporting the public body in the choice 
among different policy options through more transparent and efficient identification of the best alternative.

\section{Case description}

Interest in stećci has increased significantly since their inscription on the UNESCO World Heritage List. Several interesting recent projects have been identified by Handzic (2020). They range from digital data creation to digital data usage for research and art projects. Furthermore, they apply innovative visual techniques and tools to promote this important cultural heritage.

The case of stećci presented in this paper builds upon the author's earlier related work (Handzic \& Dizdar, 2017; Handzic, Zulic, \& Guja, 2019; Handzic, 2019; Handzic \& Ismajloska, 2019; Handzic \& Nakas, 2021). Previous work addressed only selected categories of data. In contrast, this paper brings together the analyses and visualizations of the whole spectrum of stećci-related data to facilitate knowledge acquisition and serve effective decision-making.

There are over three thousand necropolises with over seventy thousand stećci known to date. However, only a small number is cataloged and available in digital form. Thus, the visualizations presented below are based on limited samples of the available digital data to illustrate the potential of visualization in facilitating the understanding of these monuments to decision-makers.

\section{Visualizations of stećci data analyses}

Following the major trend of visual knowledge representation based on data, and not data as such (Gavrilova et al., 2017), the following visualizations represent the results of the stećci data analyses grounded in the distant reading paradigm. Originally coined by Morretti (2013) to describe an approach to analyzing literary data, the term "distant reading" refers here to the use of computational methods to uncover and present visually novel and interesting patterns in cultural heritage data. In the production of these visualizations, several sophisticated software programs were employed. These include Palladio (https://hdlab.stanford.edu/palladio/), that was specifically developed to serve the needs of digital humanists; Gephi (https://gephi.org/) that is particularly suitable for relational analyses and their graphical visualization; Adobe Photoshop (https://www.adobe.com/products/photoshop.html) which enables digital drawing; and Microsoft Excel (https://www.microsoft.com/en-us/microsoft-365/excel) for storage of digital data analyzed by other programs.

The following six figures illustrate the spatial, temporal, architectural, iconographical, epigraphical, and impact visualizations based on the analyzed stećci data.

Spatial visualization shown in Figure 1 provides knowledge of the stećci necropolises locations. Using geographic coordinates, the exact location on the map, as well as other spatial features of the heritage item (e.g. number of tombstones) or their context (e.g. buffer area size), are identified.

Temporal visualization presented in Figure 2 places these heritage assets into their historical context. It indicates the timing of stećci necropolises construction and usage duration. It facilitates the identification of the oldest or the longest-used necropolises, as well as the most prolific construction periods.

Architectural visualization in Figure 3 refers to the established typology of stećci forms (i.e. gabled, chest, slab, pillar, cross, nisan). It helps to quickly identify the dominant and/or rare forms of stećci and where they can be found. 
Similarly, iconographical visualization in Figure 4 reveals standard decoration typology (i.e. geometrical/architectural, religious/cross, heraldic/arms \& tools, astral, figural, vegetal). The presented distribution indicates the most frequent decorative motives, as well as those that are rare or unique. Epitaphs on stećci are very rare, but represent important documentary resources and hence are analyzed and visualized separately.

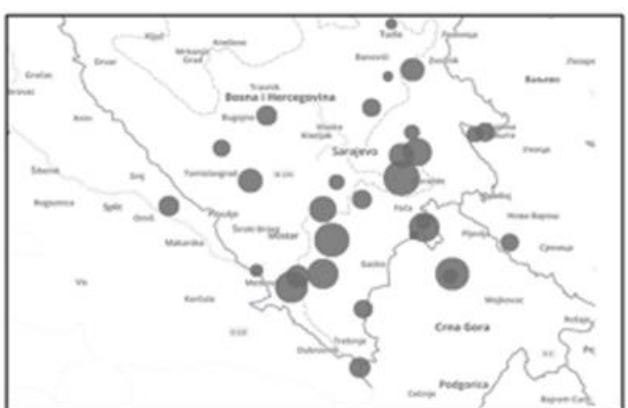

Figure 1. Spatial visualisation of 30 stecci necropolises from the UNESCO list

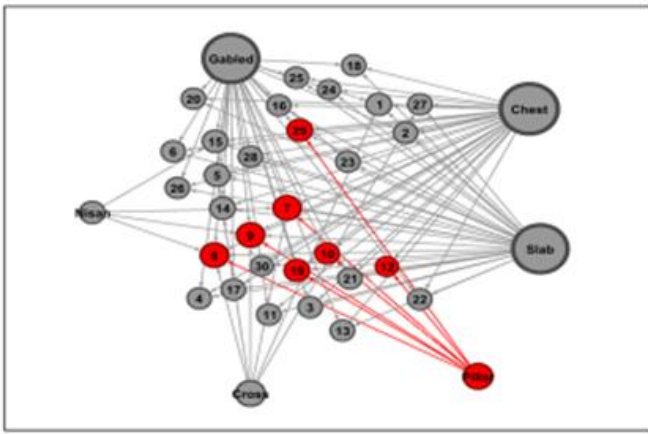

Figure 3. Architectural typology visualisation

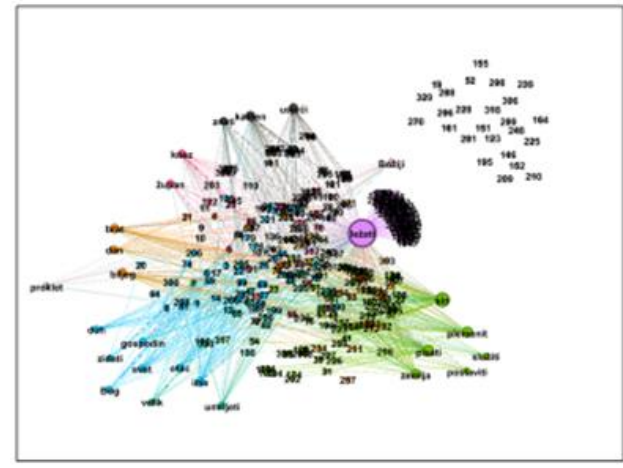

Figure 5. Text analysis visualisation of stecci inscriptions in Bosnian

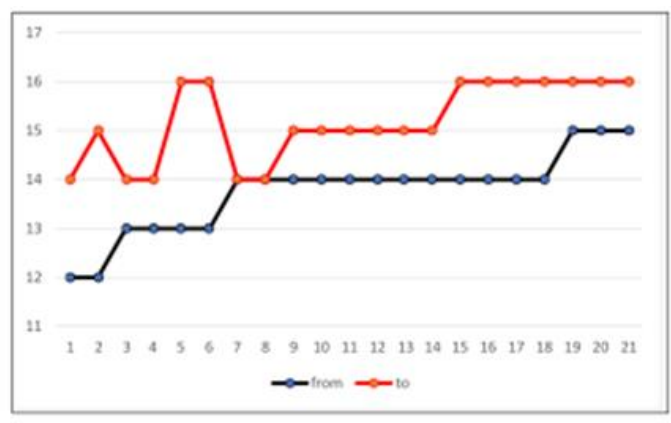

Figure 2. Temporal visualisation of 21 stecci necropolises by centuries

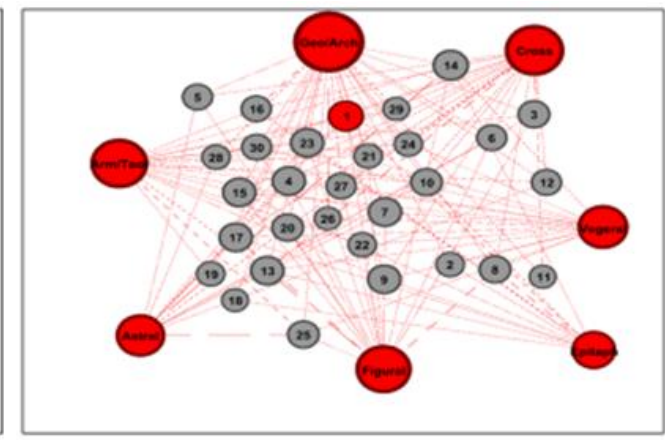

Figure 4. Iconographical typology visualisation

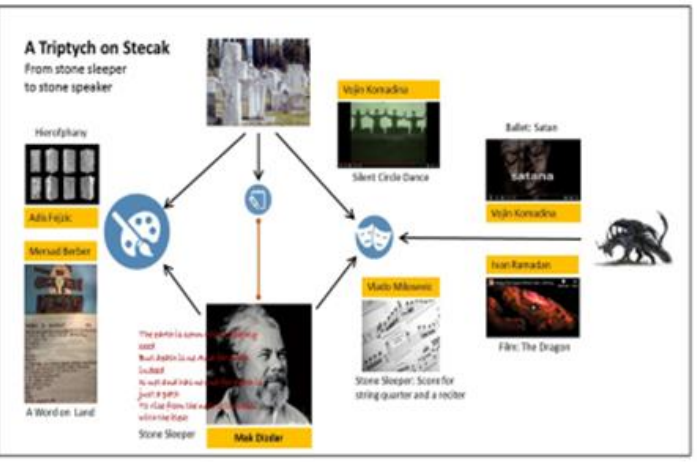

Figure 6. Visualisation of stecci impact on modern art

Epigraphical visualization shown in Figure 5 is based on text analysis of 330 inscriptions engraved on stećci stones. The modularity function of Gephi software was used to obtain major word clusters. They indicate the most prominent heroic, religious and biographical themes regarding the dead, as well as special messages intended for the living (e.g. curses and names of scribes/stonemasons). 
Finally, impact visualization in Figure 6 reveals how stećci influenced modern art and thus help in their promotion nowadays. The presented infographic recognizes the main sources and extent of stećci-related inspiration for literary, visual, and performing artists.

Missing from the above analyses and visualizations are data regarding the state of conservation, as they are not available to the author. However, once obtained, these data can be easily incorporated into the spatial visualization, for example by using semaphore color coding of decay levels.

Overall, the above data visualizations cover the majority of the recommended content of the integrated documentation protocol (Kioussi et al., 2013) necessary to support the knowledge-based decision-making process to establish priorities of cultural heritage management.

\section{Knowledge-based decision-making process}

This section describes an imaginary decision scenario in which decision-makers need to identify the stećci necropolis with the greatest potential for promoting the cultural and historic value of these heritage assets.

According to Kioussi (2013), documentation that registers various types of data lies at the heart of the integrated methodology for decision-making in cultural heritage management. The claim put forward in this paper is that visualization of the documented data can further facilitate the decision-making process by enhancing understanding and increasing the efficiency of the process.

The following simulation of the decision-making process is based on insights obtained from a series of visualizations presented in the previous section. The process uses a decision heuristic known as elimination by aspect. Heuristics are known to approximate the outcomes of the optimal decision strategies while saving the cost of time and cognitive effort of decision-makers.

The process starts with exploring the spatial visualization of stećci. This visualization clearly indicates that they are spread out all over the country, but the richest necropolises are found in the south-eastern region. This knowledge suggests that further investigation should be focused on these locations. The temporal analysis reinforces the chosen direction, as it indicates that these necropolises were established and used between the 14th and 16th centuries when the medieval kingdom of Bosnia was at its peak. In addition, longevity makes these necropolises quite valuable, allowing for tracing their historical development and change.

Another factor influencing the case heritage assessment is its stylistic analysis. With respect to architectural typology, data visualization indicates prevalent gabled forms of stećci. However, given that these types of monumental stone blocks are found in almost all considered necropolises, further analysis is required of their iconography. Here, the exploration of iconographical visualization clearly favors one necropolis that exhibits all known types of motives used for decorating stećci. It is identified as Radimlja near Stolac.

The process continues by examining stećci inscriptions. These are very rare, found in less than one percent of all stećci. Significantly, five of those are found in Radimlja. Their presence indicates that those stećci were erected as memorials for high-ranking officials and nobility. Epigraphical visualization confirms their social status, religious beliefs, and heroic death faced while serving their noble land and family.

The final step in the decision-making process considers impact visualization. It reveals one person, a poet Mak Dizdar, as the central and most influential artist promoting 
stećci. On one hand, his poetry was inspired by these "stone sleepers". On the other hand, his poetry became an inspiration to many other literary, visual, and performing artists. Interestingly, Mak Dizdar's museum (https://makdizdar.ba/category/makova-hiza-ustocu/) is located near Radimlja in his hometown of Stolac.

In summary, the above case illustrated how stećci data visualizations helped in the identification of the preferred necropolis for planning priority interventions aimed at the protection and promotion of this cultural heritage asset. More generally, the above discussion suggests that visualization of a wide range of heritage data can effectively support the knowledge-based decision-making process, leading to the right management decision.

\section{Discussion}

\section{Summary of main findings}

This article explored the role of visualization in supporting the decision-making process regarding the promotion of the Bosnian cultural heritage asset - stećci. In particular, the article introduced a series of temporal, architectural, iconographical, epigraphical, and impact visualizations to facilitate the selection of the best suitable necropolis for management intervention.

The choice of data for analysis and subsequent visualization was based on the integrated documentation protocol (Kioussi et al., 2013). It enabled taking into account all parameters related to the monument. This provided a good basis for knowledge-based decision-making and ensured the quality and transparency of the evaluation process.

The case findings reveal that the "most defensible" option from multiple points of view was selected. However, given the limited nature of case data, it is important to remember that this specific result may not be true to reality. Instead, it indicates the potential strength of the visual approach in which decision-makers can quickly and easily learn the problem while solving it (Della Spina, 2016).

\section{Implications for research and practice}

The case findings have several implications for research and practice. For research, they reinforce earlier theoretical and empirical evidence by confirming the power of visualization in facilitating knowledge discovery and interpretation and thus supporting knowledge-based decision making (Eppler \& Burkhard, 2007). "A picture is worth a thousand words" is a well-known adage expressing the same sentiment.

For practice, the visualization approach may have advantages in terms of being readily useful and easy to "read" and understand by different stakeholders, as well as by enabling transparency of the whole process. In general, the implementation of the visual approach has the potential to positively influence the ability to understand and communicate knowledge and lead to improvements in accuracy and efficiency of decision-making.

\section{Current limitations and future directions}

However, the above case findings and implications need to be considered in light of a couple of current limitations. These include a small sample of case heritage assets used in the evaluation process (due to the lack of a comprehensive digital catalog of stećci); and the adoption of a suboptimal decision method. Although, the adoption of a "satisficing" decision strategy can be justified by its ability to often improve efficiency without significantly losing on the accuracy of decision making. 
Future research is necessary to eliminate current limitations and extend current research. The growing relevance of visualization in supporting knowledge-based decision-making in general, and the lack of research in the context of cultural heritage management in particular calls for more investigations into visualization approaches, models, processes, and tools that have the potential to improve decision performance.

\section{Conclusions}

This paper addresses the general lack of studies on the visualization of cultural heritage data and its potential impact. In particular, the paper describes a specific case of stećci to illustrate the role of visualization in enhancing understanding and knowledge of cultural heritage assets to support the decision-making process in their protection and promotion. Drawing upon the statistical analyses of collected data, the paper suggests that the presented spatial, temporal, architectural, iconographical, epigraphical and impact data visualizations may serve as a useful tool for strategic planning and promotion of stećci, but also cultural heritage more generally. However, a word of caution is necessary here due to several limitations existing in the current sampling and decision strategy. Further work is necessary to systematically capture and digitize all relevant data, as well as to monitor and update them regularly.

\section{References}

Aas, T. H., \& Alaassar, A. (2018). The Impact of Visual Performance Management on Decision-Making in the Entrepreneurial Process. International Journal of Innovation Management, 22(5), 1840002. https://doi.org/10.1142/S1363919618400029

Bai, X., White, D., \& Sundaram, D. (2012). Contextual Adaptive Knowledge Visualisation Environments. The Electronic Journal of Knowledge Management, 10(1), 1-14.

CE. (2005). Council of Europe Framework Convention on the Value of Cultural Heritage for Society, Council of Europe Treaty Series No 199. https://rm.coe.int/1680083746

Della Spina, L. (2016). Evaluation Decision Support Models: Highest and Best Use Choice. Procedia-Social and Behavioural Sciences, 223, 936-943. https://doi.org/10.1016/i.sbspro.2016.05.323

Della Spina, L. (2019). Historical Cultural Heritage: Decision Making Process and Reuse Scenarios for the Enhancement of Historic Buildings. In F. Calabro, L. Della Spina, \& C. Bevilacqua (Eds.), New Metropolitan Perspectives. ISHT 2018. Smart Innovation, Systems and Technologies (vol 101). Springer. https://doi.org/10.1007/978-3-319-92102-0 47

Eppler, M. J., \& Burkhard, R. A. (2007). Visual representations in knowledge management: framework and cases. Journal of Knowledge Management, 11(4), 112-122. https://doi.org/10.1108/13673270710762756

Gavrilova, T. A., Alsufyev, A. I., \& Grinberg, E. Y. (2017). Knowledge visualization: Critique of the St. Gallen School and an analysis of contemporary trends. Business Informatics, 3(41), 7-19, https://doi.org/10.17323/1998-0663.2017.3.7.19

Gavrilova, T., Kudryavtsev, D., \& Grinberg, E. (2018). Aesthetic Knowledge Diagrams: Bridging Understanding and Communication. In M. Handzic \& D. Carlucci (Eds.), Knowledge Management, Arts and Humanities: Interdisciplinary Approaches and the Benefits of Collaboration, Knowledge Management and Organisational Learning Series (Vol. 7, ch. 6, pp. 97-117), Springer Nature.

Handzic, M. (2019). Archaeology in Contemporary Arts: A Case of Stecci, COST ARKWORK Conference: On Shifting Grounds, 3-5 October, Rethymno, Crete, https://www.arkwork.eu/archaeology-in-contemporary-arts-a-case-of-stecci/

Handzic, M. (2020). On the Digital Road: A Case of Stecci. In Proceedings of International Conference on Digital Heritage (Web-EuroMed 2020), 2-5 November 2020, Cyprus. 
Handzic, M., \& Dizdar, S. (2016). Knowledge Management Meets Humanities: A Case Study of Diplomatic Correspondence Visualisation. In Proceedings of the 11th Forum on Knowledge Asset Dynamics - Towards a New Architecture of Knowledge: Big Data, Culture and Creativity (IFKAD 2016), 15-17 June, Dresden, Germany (pp. 1445-1457).

Handzic, M., \& Dizdar, S. (2017). Picturing the Past: A Case of Knowledge Management Application in Archaeology. In Proceedings of the 12th International Forum on Knowledge Asset Dynamics - Knowledge Management in the 21st Century: Resilience, Creativity and Co-creation (IFKAD 2017), 7-9 June, St.Petersburg, Russia (pp. 1251-1261).

Handzic, M., \& Ismajloska, M. (2019). Transfering Cultural Knowledge Through Arts: Two Digital Stories In Handzic M. and Carlucci D. (Eds.), Knowledge Management, Arts and Humanities: Interdisciplinary Approaches and the Benefits of Collaboration, Knowledge Management and Organisational Learning Series (Vol. 7, ch. 5, pp. 79-96), Springer Nature.

Handzic, M., \& Nakas, L. (2021). Text Analysis of Stecci Inscriptions. COST CA15201 ARKWORK final conference (online), 10 February. https://arkwork.eu/activity/final-conference/

Handzic, M., Zulic, H., \& Guja Z. (2019). Knowledge Discovery from Arts Data: A Case of Distant Listening. In Proceedings of the 14th Forum on Knowledge Asset Dynamics - Knowledge Ecosystems and Growth (IFKAD 2019), 5-7 June, Matera, Italy (pp. 256-263).

Liu, A. (2016). DH Toychest: Digital Humanities Tools. http://dhresourcesforprojectbuilding.pbworks.com/

Kioussi, A., et al. (2013). Integrated documentation protocols enabling decision-making in cultural heritage protection. Journal of Cultural Heritage, 14S, e141-e146. https://doi.org/10.1016/j.culher.2013.01.007

Morretti, F. (2013). Distant Reading, Verso.

Munda, G. (2004). Social multi-criteria evaluation (SMCE): methodological foundation and operational consequences. European Journal of Operational Research, 158(3), 662-677.

Stabellini, B., Remondino, C. L., \& Tamborrini, P. (2017). Data visualization collection: How graphical representation can inspect and communicate sustainability through systemic design. The Design Journal, 20(1), 1673-1681. https://doi.org/10.1080/14606925.2017.1352690

Windhager, F. et al. (2019). Visualization of Cultural Heritage Collection Data: State of the Art and Future Challenges. IEEE Transactions on Visualization and Computer Graphics, 25(6), 2311-2330.

World Heritage Convention. (n.d.). Stećci Medieval Tombstone Graveyards. World Heritage List. https://whc.unesco.org/en/list/1504/

\title{
Acknowledgments
}

This article is based upon work from COST Action ARKWORK, supported by COST (European Cooperation in Science and Technology) www.cost.eu.

Received: July 20, 2021

Accepted: October 9, 2021

\begin{abstract}
Author biography
Meliha Handzic is Emeritus Professor at the International Burch University, Sarajevo. Her Ph.D. in Information Systems is from the University of New South Wales, Sydney. Meliha's research interests include knowledge management, decision support, and electronic services. She has published extensively on these topics in leading journals, conferences, and books. Currently, she is co-editor for Springer's book series Knowledge Management and Organizational Learning.
\end{abstract}

